\title{
WITTGENSTEIN ARQUITECTO: EL PENSAMIENTO COMO EDIFICIO
}

\author{
Carlos Muñoz Gutiérrez
}

Profesor de Filosofía, Universidad Complutense de Madrid

\section{El Hecho}

Entre 1926 y 1928, Ludwig Wittgenstein, el filósofo, hizo de arquitecto de la mansión, conocida como la Kundmanngasse, que su hermana, Lady Margaret Stonborough-Wittgenstein, decidió construir en Viena. En principio, la casa parece un ejemplo de arquitectura moderna temprana; pero, según los expertos, una mirada atenta revela que el diseño y muchos detalles de su construcción son tan únicos dentro del contexto de la arquitectura de comienzos de siglo como la propia filosofía (¿estética?) wittgensteiniana.

Dentro de la peculiar vida de Ludwig Wittgenstein, uno de los principales filósofos del siglo $\mathrm{xx}$, existe una singularidad que puede resultar sorprendente, si tenemos en cuenta disciplinas tan distintas como son la filosofía y la arquitectura. Para un filósofo, o al menos así lo creo, producir y ejecutar un edificio real, es decir, una casa, resulta sumamente complicado. En general, realizar algo para lo que no te has preparado resulta extremadamente complejo.

Efectivamente, al cumplirse el cincuentenario de su muerte, la biografía y la obra del pensador vienés ha generado innumerables páginas de estudios, comentarios, análisis. $Y$, sin embargo, en tan estudiada y comentada vida, este episodio ha pasado desapercibido para muchos de los biógrafos y comentaristas del filósofo. Para la importancia histórica del pensador, esta actividad es ciertamente anecdótica. La Historia no refleja cotidianeidades, ni presta atención, al menos no demasiada, a la cantidad de cosas que un ser humano relevante en algún campo de la historia humana haya podido hacer. Desde luego no, si no se considera que esa actividad haya tenido 
alguna influencia o relevancia en la tarea principal por la que recordamos al personaje.

En rigor, la dedicación de Wittgenstein a la construcción de la Kundmanngasse pasa desapercibida hasta 1951, cuando su amigo Ludwig Hänsel escribe un obituario del filósofo, en los siguientes términos:

Es significativo que durante los años entre su enseñanza en las escuelas públicas... y su cátedra [en Cambridge], construyó la villa Kundmanngasse (en el tercer distrito de Viena) para su hermana Margeret Stonborough (El asumió gradualmente el proyecto original del arquitecto P. Engelmann). Es una casa de una gran belleza espiritual, austera, noble, sin ningún ornamento. (Pensamos que próxima al estilo de Adolf Loos, de quien fue amigo, pero, yo creo, que alcanza mayor rigor.)

En 1958, G. H. von Wright, uno de los albaceas de su obra, publica un esbozo biográfico en el que describe la casa en términos similares a los usados por Hänsel. En 1964 se cita en una guía de arquitectura, Wiener Bauten 1900 bis heute, y en 1965 aparece en una revista italiana, Aut aut, un reportaje con fotografías.

Wittgenstein fue maestro de escuela, donó su fortuna para ayudar a artistas, se cuenta que tuvo como compañero a Hitler en el colegio (y que éste le odiaba profundamente), estudió ingeniería, participó en distinta medida en las dos guerras mundiales, fue hecho prisionero, y, sí también, construyó una vez una casa. Pero el episodio singular de Wittgenstein arquitecto no se cuenta entre los señalados en su vida. Y esto, aunque comprensible, tam- bién es sorprendente, porque es más que probable que nunca antes ningún filósofo haya despertado tanta curiosidad y haya sido objeto de tantas interpretaciones, estudios y polémicas.

Sin lugar a dudas, Wittgenstein es un personaje singular, entre otras cosas, por sus muchas singularidades, por su estilo de pensamiento, por sus confesiones públicas y privadas, por su docencia filosófica, por su modo de vida, y sobre todo por el vigor y la importancia de su reflexión. Pero también en gran medida, este interés lo suscita su vida y su pensamiento enigmático que ha necesitado de una interpretación. Y a la luz de las muchas interpretaciones, se han desarrollado escuelas y discípulos, seguidores y detractores, amantes y enemigos. Hay algo en él que resulta literario.

Decir que este episodio no ha recibido demasiada importancia en el contexto, es decir que sólo hay miles de páginas que lo tratan' y no decenas de miles; es decir que no se menciona en reseñas breves o biografías de contraportada. No es desconocido, pero no es popular. El objetivo de este artículo es doble, por un lado, presenta esta circunstancia vital dentro del contexto de la Viena del arquitecto Adolf Loos, por ejemplo; $y$, por otro, inicia una reflexión de fondo sobre la filosofía wittgesteiniana, tal vez sobre el pensamiento en general, que indaga en qué medida el edificio puede convertirse en metáfora interpretativa de su pensamiento, tal vez del hecho de pensar.

Me inquieta la interpretación de la filosofía de Wittgenstein que se ha hecho tradicional y 
que se difunde en los cursos generales de Filosofía, porque la considero tópica, reduccionista, sistemática. El pensamiento de Wittgenstein, por sus características, escapa a esta difusión, y -creo- que escapa principalmente porque no se ha tenido en cuenta la intención que puso el autor en sus obras, en sus manuscritos o en sus cursos. Quiero hacer una revisión de la interpretación tópica de la filosofía de Wittgenstein atendiendo a la distinta intención que puedo captar en sus notas o pensamientos, en sus experimentos mentales o en sus sugerencias. Haciéndolo así, como creo que se construye una casa, veremos que hay fases con distinto propósito, veremos que saldrán a la escena conceptos claves que no se han considerado tales, veremos que podemos enlazar la filosofía y la arquitectura en la noción de edificio. A veces, se ha lamentado que Wittgenstein no terminara el edificio de su pensamiento. Al menos podremos mostrar la Kundmanngasse en su lugar.

\section{Wittgenstein}

Ludwig Wittgenstein nació el 26 de abril de 1889, y fue el último hijo del magnate del acero y mecenas del arte Karl Wittgenstein y de su mujer Leopoldine. La familia Wittgenstein, además de una de las más ricas de la Viena de finales del siglo XIX, fue un centro de atracción de artistas, músicos e intelectuales del momento.

Aunque Wittgenstein creció en el Palais Wittgenstein en la Alleegasse, absorbiendo este ambiente de alta creación cultural, serán las habilidades de carácter técnico su primera inclinación.
En 1906 Wittgenstein se gradúa en la Königliche und Kaiserliche Oberrealschule de Linz, a donde había sido enviado después del suicidio de dos de sus hermanos. Wittgenstein decide estudiar física con Boltzmann en la Universidad de Viena, sin embargo ese mismo año Boltzmann se suicida también, lo que frustra su decisión. Terminará estudiando ingeniería mecánica en la Technische Hochschule en Berlin-Charlottenburg.

Dos años más tarde Wittgenstein parte para Inglaterra para estudiar ingeniería aeronáutica en el famoso departamento de ingeniería de la Universidad de Manchester. Antes había realizado experimentos con nuevos tipos de cometas para la investigación meteorológica en Glossop, Cheshire.

En la Universidad de Manchester desarrolla un motor a reacción asociado a un propulsor que le dirige. El principio había sido ya descrito por Herón de Alejandría, a quien seguramente Wittgenstein había leído en la biblioteca de su padre. En el eje del propulsor se construía una cámara de combustión de volumen variable, mientras que la reacción a chorro se asociaba a las puntas de la aspas. El prototipo que construyó funcionó y aunque llegó a patentarlo, el problema de impermeabilización de los gases expandidos resultó insuperable.

El problema de la forma aerodinámica óptima del propulsor era un problema esencialmente matemático y parece que fue esto lo que le llevó a Wittgenstein a interesarse por el estudio de la Matemática. Es conocido que al partir hacia Inglaterra ya llevaba en su equipaje la 
obra de Frege a quien admiraba notoriamente. A raíz de este interés por la matemática sus intereses filosóficos vuelven a florecer.

En 1912 Wittgenstein decide interrumpir sus investigaciones en Manchester y estudiar Lógica matemática con Russell en Cambridge.

Parece ser que Wittgenstein tenía ya por entonces un estilo elaborado y conocido respecto al diseño y la arquitectura. C. M. Mason, que era asistente en el laboratorio donde Wittgenstein trabaja en su prototipo de motor aeronáutico, declara que sus conversaciones sobre arquitectura y diseño eran frecuentes. Otro ejemplo significativo de esa personalidad y estilo fue la dificultad que encontró en Cambridge para amueblar sus habitaciones, llegando a ordenar un diseño de muebles que encajaba con el grado de simpli-

120 cidad que buscaba.

Su amigo William Eccles, a quien conoció en Glossop y que estudió ingeniería con él en Manchester, intercambió cartas con él pidiéndole consejo respecto a la decoración de su casa y, especialmente, sobre los aspectos eléctricos y mecánicos. En una carta fechada el 28 de junio de 1914 en Manchester, Eccles escribe a Wittgenstein lo siguiente:

«El mobiliario está completo (parcialmente gracias a ti por muchas razones). La decoración ha sido diseñada o mejor planeada por Ada excepto en la habitación de dibujo que es una copia de tu habitación en Cambridge (alfombra azul, pintura negra, paredes amarillas) excepto en que el techo y alrededor de dos pies en las paredes es blanco y la iluminación indirecta, i.e. reflejada desde el techo.
Los elementos eléctricos, especialmente la cocina que es francamente buena, son tan limpios y cómodos. Los radiadores son también excelentes y no tenemos necesidad de fuego...»

Continúa después indicándole a Wittgenstein las líneas generales de estilo que ha seguido en la construcción y decoración, destacando la simplicidad como la nota prioritaria.

Wittgenstein le contesta desde Viena, dándole los siguientes consejos:

«...tus diseños son espléndidos en la medida en que puedo juzgarlos. Te haré algunas observaciones: 1. el guardarropa - ¿por qué el travesaño horizontal de las puertas no está en el medio (de arriba abajo), de tal manera que los paneles superior e inferior sean de la misma longitud? 2. Pienso que podría quizá ser más conveniente descansar el armario en una baja (3") V en la base como está en el diseño del constructor en vez de que las puertas se abran hacia la derecha sobre la alfombra...»

Continúa posteriormente dándole indicaciones sobre cómo debería ser la cama, preguntando a Eccles por qué debería tener ruedas si «tu no vas a viajar en ella por la casa». Sin duda, este tipo de correspondencia puede resultar sorprendente en la figura del filósofo. Efectivamente, tendemos a ser reduccionistas y a simplificar la realidad según las interpretaciones tópicas que hacemos de ella. Wittgenstein se rebela constantemente a esa simplificación que tendemos a hacer de su vida y de su pensamiento.

En la primavera de 1914, Ludwig construye su primera y única casa cerca del pueblo 
Noruego de Skjolden a la orilla de Sognefjord, en donde pasará períodos de soledad y de trabajo filosófico. La casa fue construida en madera al estilo local; era modesta, con una base, un planta de suelo con pocas habitaciones y un ático. Aunque no está documentada, recuerdos de los amigos que la conocieron indican que tenía detalles ingeniosos. Como estaba situada en un acantilado abrupto sobre el lago (sólo se podía llegar remando) dispuso, entre otras cosas, un cabrestante con un cable del que colgaba un cubo con el que coger agua.

A comienzos de julio de 1914, Wittgenstein vuelve a Austria para arreglar los asuntos relativos a la herencia recibida tras la muerte de su padre ocurrida el año anterior. Allí contacta con el editor Ludwig von Ficker y le pide que distribuya cerca de 100.000 coronas entre artistas de su elección con la única condición que se dé a conocer el nombre del benefactor. De esta donación se van a beneficiar: George Trakl, Rilke, Kokoschka, Else Lasker-Schüler o el arquitecto Adolf Loos, a quien Wittgenstein admiraba y que le fue presentado ese mismo mes por von Ficker. Von Ficker, al que Wittgenstein había elegido como distribuidor de su fortuna atendiendo a unas palabras de Karl Kraus que le consideraba el único editor honesto de Austria, preparó un encuentro entre Wittgenstein y Adolf Loos. Presentación que ocurrió el 27 de julio de 1914 en el Café Imperial. Aunque no se conoce el contenido de esa conversación, el resultado fue una larga amistad que duró hasta la muerte de Loos en 1933.
Iniciada la primera guerra mundial, Wittgenstein se presentó voluntario y pasaría por diversas vicisitudes bélicas durante los cuatro años siguientes, que han quedado recogidos en sus Diarios Secretos. Durante el periodo de la confrontación mundial, siempre que volvía a Viena visitaba a Loos. Fue él quien, en 1916, le encaminó hacia Paul Engelmann, uno de sus discípulos, que vivía en Olmütz (actualmente Olomouc en la república Che-ca). Durante unas sesiones de entrenamiento que Wittgenstein pasó allí se hicieron buenos amigos. A partir de esa amistad debemos situar el episodio que nos ocupa, a saber, el encargo por parte de la hermana de Wittgenstein del diseño de su casa.

Las coincidencias programáticas y de estilo entre Loos y Wittgenstein, a primera vista, debían de asegurar una comunión evidente. Sin embargo, hay una profunda diferencia que aparecerá conforme los caminos del arquitecto y del filósofo se perfilen nítidamente. Loos, que había adquirido su estética funcional a raíz de un viaje a Estados Unidos e Inglaterra y de una revisión de la arquitectura clásica romana, era, a pesar de todo, un artista cuyo planteamiento funcionalista indagaba en una mejora de la existencia terrenal y material. Para Wittgenstein, en donde, como veremos posteriormente, ética y estética mantienen una especial equivalencia, y deben mantenerla, su estilo funcional (tal vez minimal) debía ser un alivio contra la maldad, el exceso, y el espanto que le producía la vida cotidiana. Contra el lema loosiano, «Das Praktische ist schön» (Lo funcional es bello), Wittgenstein podría haber producido «Nada que me distraiga, nada que me aleje de lo importante» 
No es extraño que, a la vuelta de la guerra en 1919, liberado de su encierro en Monte Cassino, escriba a Engelmann lo siguiente:

«Hace unos días vi a Loos. Fue horrible y nauseabundo. ¡Él ha quedado infectado con el más virulento fingido intelectualismo! Me dio un panfleto2 sobre una propuesta 'oficina de las Bellas Artes', en donde habla sobre un pecado contra el Espíritu Santo. ¡Esto seguramente es el colmo! Yo andaba un poco deprimido cuando me encontré con Loos, pero esto fue la última gota que colmó el vaso.»

Poco más se sabe de esta relación, pero es significativa la dedicatoria que Loos pone en un artículo, Ins Leere gesprochen (Dicho en el vacío) que había publicado en el periódico Neue Freie Presse en 1921, que regala a Wittgenstein en 1924 cuando Loos abandona

«A Ludwig Wittgenstein, con gratitud y muy afectuosamente, agradecido por su inspiración, muy afectuoso en la esperanza de que me devuelva este sentimiento.»

Esto no significa que se rompiera la amistad entre ellos, pues existe correspondencia de Wittgenstein a Loos del año 1925, cuando Wittgenstein afronta el segundo intento de ser maestro de pueblo en una zona deprimida de Austria, y nuevos encuentros en Viena en años posteriores, incluso durante el diseño y la construcción de la Kundmanngasse, pero, sin duda, muestra al menos un recelo conocido por ambos. Tampoco parece que Loos estuviera muy contento por lo que consideraba una intromisión de Wittgenstein en la profesión, cuanto más porque el diseño inicial

del edificio había estado en manos de su discípulo Engelmann.

\section{El Filósofo del Tractatus}

En 1921 (en 1922 la traducción inglesa), se publicó la obra de Wittgenstein, el Tractatus Logico-Philosophicus, la única que voluntariamente mandó a un editor. A pesar de lo cual tampoco podría afirmarse que fuera Wittgenstein un filósofo profesional. Como vemos, después de la guerra se dedica a la enseñanza en zonas deprimidas de Austria. Ciertamente, según él mismo expresa, en filosofía, después del Tractatus, ya está todo resuelto por lo que ya no cabe una dedicación continuada a la reflexión filosófica.

El Tractatus es hoy sin duda una obra impresionante, sobrecoge por muchos motivos. En mi caso quizá porque después de dedicarle muchos esfuerzos para comprenderla, no alcanzo a ver su intención. En la obra posterior de Wittgenstein esta intención suele estar mucho más clara, pero en el Tractatus se produce -creo- un extraño giro, que ha sido habitual en filosofía desde la obra de Nietzsche, cuando todo está claro, cuando se ha logrado una representación exacta del mundo, se demuestra que ésta no soluciona nada, no aporta ninguna respuesta, no aquieta nuestras intranquilidades humanas, no resuelve ningún enigma. Lo que enseña el Tractatus es que «De lo que no se puede hablar, mejor es callarse».

Por otro lado, como el propio Wittgenstein escribe a Russell durante la guerra, el Tracta- 
tus es el resultado de elaborar sus pensamientos en forma de Tratado, en este sentido el Tractatus sobrecoge también.

Su arquitectura elaborada con una firmeza singular recorre, digamos, un camino hasta que en un momento vuelve atrás para autocontenerse, como una muñeca rusa. Wittgenstein dice lo que no se muestra y muestra lo que no puede decirse. No es extraña tampoco la elección arquitectónica que usará para edificar el pensamiento. Quizá lo más sorprendente sea que ya nunca más pudo volver a repetirla.

No es éste el lugar para estudiar en profundidad el contenido filosófico del Tractatus, pero sí quiero indicar algunas pistas en la medida en que, en esta ocasión, rastreamos esa actividad, anecdótica al fin, del Wittgenstein arquitecto.

Voy a centrarme en un pasaje del Tractatus no demasiado citado en los estudios filosóficos, porque al ser consecuencia de las principales líneas de pensamiento no resulta central a la teoría wittgenstiana de estos años. Sin embargo, su plasticidad nos muestra fácilmente dos cosas. Por un lado, expresa la tarea de la fílosofía y de la ciencia, que será posteriormente uno de los temas preferidos de reflexión por parte de Wittgenstein; y, por otro, enlaza perfectamente bien con mi intención de obtener de la filosofía de Wittgenstein la metáfora del edificio como expresión del hecho del pensar (al menos, de un cierto pensar).

El pasaje al que me voy a referir va desde 6.34 hasta el parágrafo 7 con el que concluye la obra recomendándonos el silencio, como ya hemos mencionado. En dos de los más extensos parágrafos que podemos encontrar en el Tractatus dice Wittgenstein lo siguiente:

6.341. La mecánica newtoniana, por ejemplo, reduce la descripción del universo a una forma unitaria. Imaginémonos una superficie blanca con manchas negras irregulares. Digamos: Cualquier clase de figura que resulte puedo siempre aproximarla, tanto cuanto quiera, a su descripción si cubro la superficie con una malla reticular suficientemente fina, diciendo de cada cuadrícula que es blanca o negra. Habré reducido así la descripción de la superficie a una forma unitaria. Esta forma es arbitraria, pues yo hubiese podido aplicar con igual éxito una malla con aberturas triangulares o hexagonales. Pudiera ocurrir que la descripción hecha con una malla triangular fuese más sencilla; esto quiere decir que con una malla triangular más gruesa podríamos describir la superficie más exactamente que con una cuadrangular más fina, o al revés, y así sucesivamente.

A las diferentes mallas corresponden diversos sistemas de descripción del universo. La mecánica determina una forma de descripción diciendo: todas las proposiciones de la descripción del mundo deben obtenerse de un modo dado por un número dado de proposiciones - los axiomas de la mecánica-. Proporciona los ladrillos para construir el edificio de la ciencia y dice: cualquier edificio que tú quisieras levantar lo debes construir siempre con estos y sólo con estos ladrillos.

(Lo mismo que con el sistema de los números se debe ser capaz de escribir arbitrariamente cualquier número, así con el sistema de la mecánica se debe poder escribir arbitrariamente cualquier proposición de la física.) 
6.342 Ahora vemos la recíproca posición de la lógica y la mecánica. (Se podría construir la malla con figuras de diferentes clases; por ejemplo, con triángulos y hexágonos.) Que una figura como la arriba citada se pueda describir por una malla de una forma dada no dice nada sobre la figura misma. (Pues esto es válido para todas las figuras de esta clase.) Pero aquello que caracteriza a la figura es el hecho de que se la pueda describir completamente con una determinada malla de determinada finura.

Así, pues, nada dice acerca del universo que se le pueda describir por la mecánica newtoniana; pero sí dice algo que se le puede describir así como de hecho se le describe. Y también dice algo sobre el mundo que se le pueda describir más sencillamente por una mecánica que por otra.

Estos pasajes resumen, a la vez, el esfuerzo que Wittgenstein emprendió para edificar (las

cursivas de la cita son mías) un representación de la forma de la representación exacta del mundo. La ciencia empírica, la mecánica en este caso, construye una representación y aunque no nos dice nada sobre el mundo, excepto quizá que encaja en esa representación, muestra al menos que «las cosas están así». Desde luego, lo que podemos hacer ahora es hablar sobre la malla (la representación) y describirla o analizarla. Creamos así la propia idea de ley, aunque en virtud del completo aparato lógico que contiene la mecánica, «las leyes físicas hablan aún de los objetos del mundo» (T. 6.3431)

Efectivamente, uno de los errores del pensamiento humano es pensar que lo que podemos encontrar en la malla con la que describimos el mundo, es el mundo o pertenece al mundo.
Lo que sea el mundo no puede expresarse, y las leyes con las que describimos el comportamiento de la naturaleza no hablan de nada sino que son a lo sumo nombres de clases, elaboradas a priori, son meras posibilidades lógica. Puesto que la lógica inunda el pensamiento y puesto que no podemos escapar a la lógica, la figura lógica de los hechos es el pensamiento (T. 3)

El Tractatus va a seleccionar la lógica como una figura a la vez de la realidad y del pensamiento. La lógica se convierte así en la forma de la forma de la representación exacta, porque efectivamente «podemos hacernos figuras de los hechos» (T. 2.1).

El pensar produce entonces una construcción a escala del edificio del mundo, pero, y aquí radica la tragedia, cuando comenzamos a edificar el pensamiento con los ladrillos que nos proporciona y sólo nos los proporciona la lógica, estamos haciéndolo desde dentro, de suerte que al final, el edificio muestra lo que nosotros encerrados en su interior no podemos contemplar. La figura del edificio será una réplica exacta del mundo, pero desde dentro nada podemos hacer sino seguir nuestra existencia como lo hacíamos antes de construirlo. La filosofía aparece cuando una y otra vez queremos salir afuera para poder contemplar nuestra representación a escala como un todo, pero no hay salidas ni ventanas en ella, pues el mundo tampoco las tiene. Estamos encerrados en nosotros mismos, somos nuestros límites y aunque la maqueta muestre qué puede ser el mundo, nosotros sólo podemos expresar que seguimos sin comprender el mundo que hemos podido describir. 
Esta es probablemente la consecuencia más inadmisible para el propio Wittgenstein, que posteriormente se dedicará a combatir vigorosamente. Bien es verdad que la solución queda condicionada a una reconsideración del lenguaje que va dejando de ser el vehículo del pensamiento, que va dejando de ser representacional.

La consecuencia más inadmisible que Wittgenstein descubre ya en el Tractatus es lo que en filosofía se denomina solipsismo.

En 5.62 encontramos la siguiente afirmación que más parece un lamento desesperanzado: «Lo que el solipsismo significa es totalmente correcto...». El solipsismo, en último término, significa en primer lugar que no podemos escapar a nuestra representación del mundo, no podemos escapar del edificio construido, pero además en el edificio sólo cabemos nosotros que lo hemos construido. Lo que el solipsismo significa es que el mundo es mi mundo, que mundo y vida son una sola cosa. Mi pensamiento puede edificar toda suerte de representaciones, pero éstas, que a lo sumo muestran lo que representan. Son mías, no puedo escapar de mi posición, incluso las representaciones de otros, si las hubiera, tendría que integrarlas en las mías propias. Tengo yo que enjuiciar el mundo desde mi posición. De tal manera nuestro pensamiento es el límite más allá del cual nada puede quedar. Sin embargo, nos encontramos enfrentados a un mundo que nos es inaccesible porque sólo podemos representárnoslo.

A la vez, «el mundo es independiente de mi voluntad» (T. 6.373). Por eso no hay valor en el mundo y no hay deseo que pueda producirse en el mundo directamente por nuestra voluntad. En este caso, el deseo de escapar a nuestro pensamiento como forma de figuración o a nuestro lenguaje que es la expresión del pensamiento, nos coloca en el ámbito de lo transcendental, de lo que está más allá de los límites del mundo.

Cuando Wittgenstein descubre en las secciones finales del Tractatus las consecuencias de su planteamiento figurativo, ya no hay escapatoria y comprende que:

6.53. El verdadero método de la filosofía sería propiamente éste: no decir nada, sino aquello que se puede decir; es decir, las proposiciones de la ciencia natural -algo, pues, que no tiene nada que ver con la filosofía-; y siempre que alguien quisiera decir algo de carácter metafísico, demostrarle que no ha dado significado a ciertos signos en sus proposiciones. Este método dejaría descontentos a los 125 demás -pues no tendrían el sentimiento de que estábamos enseñándoles filosofía-, pero sería el único estrictamente correcto.

6.54. Mis proposiciones son esclarecedoras de este modo; que quien me comprende acaba por reconocer que carecen de sentido, siempre que el que comprenda haya salido a través de ellas fuera de ellas. (Debe, pues, por así decirlo, tirar la escalera después de haber subido).

Nuestro pensamiento es entonces una escalera que habrá que destruir una vez hecho uso de ella. Podemos escapar a todas las consecuencias negativas del Tractatus (fundamentalmente el problema del solipsismo, es decir, nuestro encierro en el edificio construido) si distinguimos claramente lo que puede decirse de lo que sólo puede mostrarse. 
Una consecuencia ya mencionada e inevitable es que la estética y la ética no se distinguen (Ética y Estética son lo mismo o son uno -sind Eins- T.6.421). Evidentemente, el sentido del mundo debe quedar fuera del mundo y la ciencia no puede decirnos nada sobre ello. En el mundo no hay valor y nuestra acción en él no altera su estructura. La estética es un asunto de creencia y la creencia escapa a la lógica del mundo, a lo sumo cristaliza un conjunto de modos de pensar y actuar.

Lo que la estética o la ética expresa es la experiencia que se tiene ante el mundo. Esta experiencia se resume en: «me asombro ante la existencia del mundo» (CE, p. 38). La estética, la ética y en general, como hemos indicado, lo que el filósofo califica de transcendental, es el impulso del hombre por arremeter contra los límites del lenguaje, del edificio que se construye con los ladrillos del lenguaje. El asombro -le decía en una carta a M. Schlick (30-12-1929)- no se puede expresar en forma de pregunta y en consecuencia tampoco hay respuesta para él. Si ha de haber alguna diferencia entre todo lo transcendental, contra todos esos impulso por arremeter contra los límites, reside en que la tendencia apunta hacia algo. Volviendo a ejemplos arquitectónicos, que Witgenstein utiliza recurrentemente en toda su obra y que ahora preferiré emplear antes que otros, podemos ver hacia donde apunta cuando lo transcendental se desliza hacia lo estético.

7. Supongan que construimos casas y que damos a las puertas y ventanas ciertas dimensiones. ¿Se muestra necesariamente en algo que decimos el hecho de que nos agraden esas dimensiones? ¿Lo que nos agrada es mostrado necesariamente por una expresión de agrado? Supongan que nuestros hijos dibujan ventanas y que cuando las dibujan mal les castigamos. O que cuando alguien construye una casa determinada rehusamos vivir en ella o salimos corriendo. (Lecciones sobre Estética pp. 77-78.)

No hay causas que produzcan el asombro estético o ético, no hay causas que nos obliguen a traspasar los límites del mundo. Lo transcendental expresa las inclinaciones del hombre por buscar sentido. El tamaño de las ventanas no puede ser causa de mi desagrado, sino que éste expresa una tendencia mía ante ellas. El asombro ante el mundo nos impulsa a encontrarle una causa, pero ésta, de haberla, no puede estar en el mundo. No hay valor en el mundo, sólo hechos. El agrado o el desagrado ante el tamaño de las ventanas no algo de la ventana sino que expresa mi relación con ellas.

Efectivamente, vemos la diferencia entre Loos, el arquitecto, y Wittgenstein, el filósofo. Loos o la arquitectura en general pueden empeñarse en construir edificios que sobre el mundo constituyan fortalezas que nos protejan de sus peligros. Pero Wittgenstein tiene necesariamente que arrostrar los peligros del mundo, golpearse una y otra vez contra sus paredes que tanto desearía traspasar.

Wittgenstein conoce otra solución a la cadena imparable de representaciones exactas que es el edificio del pensamiento: salir al exterior, no construir sino diluirse en el todo, fundirse en la malla y poder contemplar el mundo como un todo, «sub specie aeterni». Esto es 
la mística, tal vez el programa de su vida austera y minimalista, que al final o no logró su culminación o bien, si lo hizo, no podía expresarse con el lenguaje tal como él mismo ya sabía.

Engelmann vio perfectamente bien esta diferencia, o esta actitud diversa entre Loos y Wittgenestein, y Kraus:

«Loos separa el objeto de uso del arte y mata a su hijo natural común, el ornamento. Kraus separa la vida del lenguaje y mata a su hijo natural común, la frase vacía. Wittgenstein separa a la ciencia del misticismo y mata a su hijo natural común, la filosofía.»

\section{Wittgenstein Arquitecto}

Sin duda, la personalidad de Wittgenstein era especial. Después de varios intentos abandonó definitivamente la idea de enseñar a niños. Debía ser un profesor irascible e impaciente, que exigía a sus alumnos tanto como a sí mismo. El caso es que en la primavera de 1926 , un incidente con un alumno y una posterior acusación contra su estilo de enseñanza y sus castigos le llevó a dimitir de su puesto creándole un estado de inseguridad y un sentimiento moral de fracaso. Definitivamente se consideraba no apto para la profesión. Incluso antes de su dimisión formal, ya tenía un empleo como jardinero en el monasterio de los hermanos de la Caridad en Hütteldorf, un suburbio de Viena, lo que demuestra que llevaba tiempo considerando su incapacidad como maestro.

El 3 de junio de 1926, muere su madre, lo que agranda su crisis personal y moral. Dada la situación depresiva de Wittgenstein, su her- mana y su amigo Paul Engelmann le sugieren la idea de que participe como co-arquitecto en el diseño de la mansión de su hermana Margaret. Un proyecto por el que Wittgenstein había mostrado siempre interés. Conocemos también por este época testimonios que indican la intención de Wittgenstein de dedicarse a la arquitectura, por lo que acometer la empresa podía servir para ponerse a prueba ante esta profesión.

Después de un meditada y confusa reflexión, acepta el proyecto. En el otoño de 1926 encontramos ya a Wittgenstein en el número 18 de Parkgasse, una casa que su hermana había heredado y que se constituirá en la sede de la empresa arquitectónica.

Antes, en noviembre de 1925, Margaret Stonborough había invitado a Engelmann a su casa de campo, Toscana Park, en Gmunden y 127 le había hablado de sus planes de construir una gran casa en Viena. Durante los meses de abril y mayo de 1926, Paul Engelmann dibujó una serie de bocetos en cooperación con la propia Margaret, que recibieron los comentarios de Wittgenstein. Esta primera elaboración de Engelmann se constituyó en el diseño básico de la planta baja y de la disposición espacial de la Kundmanngasse.

Wittgenstein se fue involucrando en el proyecto poco a poco. El propio Engelmann en una carta a von Hayek, indica la importante colaboración y ayuda que suponen sus consejos, pues -dice- «Me parece que él [Wittgenstein] comprende la intenciones de Frau St. mucho mejor que yo.» Después comenta el estado depresivo en el que se encontraba Lud- 
wig y expresa su ofrecimiento para que Wittgenstein trabajara de lleno en el proyecto, relata, más adelante, su respuesta afirmativa. Al final de la carta, le indica Engelmann a von Hayek que considera que la realización del edificio es obra de Wittgenstein y no suya.

El progresivo alejamiento del proyecto que experimenta Engelmann puede haberse debido precisamente a las limitaciones que Margaret puso a su libertad creadora. Parece incluso que Engelmann, amigo de Wittgenstein desde hacía tiempo, podía haber pensado que su participación en el proyecto, suavizaría las diferencias con su hermana. Pero la perseverancia y dedicación de Wittgenstein desde el primer día avasallaron a Paul. Así lo expresa el propio Engelmann:

«Hasta entonces, yo había conocido y admirado su dimensión intelectual y emocional, después descubrí su fuerte voluntad. Durante aquellos dos años de colaboración continua yo sólo podía soportar su superioridad y su manera inflexible de llevar a cabo sus propios planes incluso a través de importantes dificultades.»

Los primero planos para solicitar el permiso de edificación están fechados el 13 de noviembre de 1926 y fueron firmados a la vez por Engelmann y Wittgenstein. Pero en 1928 Engelmann se fue a Olomouc y no volvió hasta que la Kundmanngasse estaba terminada. Efectivamente, los planos subsiguientes llevan exclusivamente la firma de Wittgenstein.

Hubo otra persona implicada en el proyecto, Jacques Groag, también un discípulo de Loos, quien se encargó de la supervisión de las especificaciones y los cálculos de costes de la construcción. Al fin y al cabo Engelmann tenía poca experiencia en estas tares, pues fundamentalmente se había dedicado al diseño de interiores y la formación en ingeniería mecánica de Wittgenstein tampoco era la adecuada para estas tareas.

Cabe pensar que Engelmann se sintió tan desplazado del trabajo y superfluo, que prefirió abandonarlo y así evitar cualquier desavenencia con su amigo.

De todas formas, la relación entre Wittgenstein y Paul se fue perdiendo. Poco a poco al principio y del todo a partir de 1937, -Engelmann emigró a Palestina en 1934-. No obstante Engelmann ha jugado un importante papel en la difusión del pensamiento de Wittgenstein. Fue él el primero en difundir la interpretación del Tractatus y de la intención filosófica de Wittgenstein como fundamentalmente ética, tal y como durante tantas conversaciones Wittgenstein le expuso. Lo hizo contra la interpretación anglosajona que mostraba a la figura filosófica del excéntrico austríaco exclusivamente como un genio en cuestiones técnicas sobre lógica y filosofía del lenguaje y al Tractatus como un producto de esta y sólo esta preocupación. A decir verdad, no estoy convencido de si todavía hoy se entiende adecuadamente a Wittgenstein en el ámbito filosófico anglosajón.

Respecto al plan inicial de Engelmann, Wittgenstein amplió la planta baja, revisó las proporciones del edificio y eliminó toda decoración y ornamento. Él mismo diseñó todos los componentes mecánicos, seleccionó los mate- 
riales usados en el interior y en el acabado del exterior, incluyendo cerrojos, cerraduras y picaportes, y también la instalación eléctrica y la fontanería.

La idea de estilo que aportaba Wittgenstein al proyecto era evidente: Las dimensiones de las habitaciones y las divisiones de planos entre paredes y suelo seguirían un armonía proporcional, los colores se eligieron por su transparencia y discreción, los materiales por su durabilidad y su no notoriedad. La casa debía ser un contenedor para lo importante: sus habitantes, sus muebles, las obras valiosas. Su belleza la depositaba Wittgenstein en la pureza y claridad de la edificación.

Su hermana Hermine relata este proceso en sus Familienerinnerungen:

«Ludwig diseñó cada ventana y puerta, cada cierre de ventana y radiador, con tal cuidado y atención al detalle como si fueran instrumentos de precisión, y a la vez de forma sumamente elegante. $\mathrm{Y}$ entonces, con su incansable energía, se aseguraba de que todo se realizara con el mismo meticuloso cuidado. Todavía puedo escuchar al cerrajero preguntándole, respecto a una cerradura, «Dígame Señor Ingeniero, ¿es tan importante un milímetro aquí o allá?» Incluso antes de que terminara de hablar, Ludwig contestó tan alto y vigorosamente «jSí!» que el hombre casi salta del susto. En verdad, Ludwig tenía tal sensibilidad para las proporciones que a menudo medio milímetro era importante.»

En este sentido, es significativa la anotación que hace Wittgenstein en sus diarios con fecha de 11.3.31 [Manuscrito MS 183] :
Una extraordinaria observación de Engelmann que me vuelve a la cabeza a menudo: Durante la construcción de la casa en la época en que todavía trabajábamos juntos tras una conversación con el contratista de obras me dijo: “ ${ }_{\text {Usted no puede }}$ hablar lógica con esa persona!»-Yo:" «Le enseñaré lógica»-Él: «Y él le enseñará psicología».

En el invierno de 1927, el trabajo estructural de la Kundmanngasse estaba prácticamente terminado y el uno de octubre de 1928, se concedió el permiso para poder habitar la casa a condición de que se instalara una alarma en el ascensor y de que el hueco entre las puertas de la cabina del ascensor y las paredes se estrechara. Ese mes Margaret Stonborough y su familia se mudaron a la casa.

\section{La Kundmanngasse}

La alta, austera y casi blanca estructura de la Kundmanngasse ofrecía un fuerte contraste con los frondosos árboles del jardín que la rodeaban. El único elemento abierto es un porche, al sur con sus amplios escalones y ventanales adyacentes al hall. La casa ofrece una inmediata impresión de solidez y austeridad. Sin embargo, no ofrece un aspecto monolítico sobre un cuidado jardín. Al contrario, la naturaleza monumental del edificio resulta elegantemente rodeada por el jardín, creando una deliberada fusión de naturaleza y cultura.

El bloque central avanza como si fuera a adelantar a un segundo bloque diagonal y a las dos terrazas; crea así un efecto dinámico que es enfatizado por el tercer bloque que, de dimensiones menores, repite el mismo movimiento hacia delante sobre la terraza sur. 
La planta central de la Kundmanngasse, en la versión definitiva después de las modificaciones realizadas por Wittgenstein, contendrá las habitaciones comunes de la familia: un vestíbulo, un Saal (que servirá también como habitación de música), el comedor, la terraza sur, la escalera, la sala de estar (que servirá también como biblioteca), y el comedor para el desayuno, dispuesto todo ello de forma simétrica, lo que contrasta con la asimetría del exterior.

El plano de la planta principal muestra rápidamente las intenciones de Wittgenstein y de su hermana; el bloque poco profundo añadido a la fachada trasera será el lugar destinado a ubicar las habitaciones de Margaret, mientras que el resto de las habitaciones irán en los pisos superiores. En este bloque trasero, Wittgenstein incluye un salón, un vestidor, un baño y una habitación para el servicio, además de un pasillo que va desde el salón a la escalera central. en el que hay todavía espacio para un aseo, una despensa amplia detrás del comedor, una entrada separada para el servicio en la parte trasera de la casa y el hueco por donde circularan el ascensor y la escalera.

El segundo piso contiene habitaciones para los niños, la institutriz, los invitados y los sirvientes así como dos baños.

Finalmente, en el sótano, encontramos unos nichos en donde se ubicarían las cortinas metálicas que cubrirían las ventanas de la planta principal. Además, se encuentra allí el comedor de la servidumbre, la habitación de la caldera, el garaje y el depósito de fuel. La cocina, también en el sótano, estaba situada debajo de la despensa y el comedor

La fuerza del «gesto arquitectural» de la Kundmanngasse -expresión que el propio Wittgenstein usaba para indicar el poder expresivo que podía llegar a tener la arquitectura- radica en la indistinción entre la vertical y la horizontal y, desde luego, en la asimetría de su disposición cubica. A diferencia del proyecto de Engelmann, en el de Wittgenstein toman más fuerza los planos de pared que los de ventana. La distancia horizontal entre ventanas es menor que la distancia desde las ventanas a los bordes de la pared, mientras que los parapetos de las terrazas son extensiones de las elevaciones superiores. Las ventanas son más altas que anchas, con divisiones sólo verticales, disminuyendo en altura además, según la altura de los pisos, lo que produce un efecto de edificación más estilizada. La tendencia ascendente del edificio es atemperada por las claras líneas horizontales que marcan el final de los planos de pared; no hay canalones para evacuar agua y los filos del tejado o de las terrazas se reducen al mínimo. Posiblemente la regla de Wittgenstein haya sido: Cada plano tiene su propio eje vertical de progresión y siempre que un plano esté paralelo a otro, sus ejes verticales no coinciden, creándose así un tensión interplanar. Conversamente, siempre que el eje vertical de los vanos de las ventanas cambie, hay también planos paralelos de pared. Todo esto contribuye a dar esa impresión despejada que produce la casa

Hemos mencionado que los dibujos técnicos y los cálculos de las especificaciones del edificio, fueron realizados por otro discípulo de Loos 
con más experiencia en edificación, Jacques Groag. Sin duda, Groag conocía las técnicas arquitectónicas más actuales del momento. La Kundmanngasse fue construida según estas últimas tendencias. Sus muros de carga de ladrillo estucado encubren una estructura de hormigón, estando algunos de los pilares reforzados. Nervios de hormigón sostenidos por vigas igualmente de hormigón descansan en los puntales y las paredes exteriores apuntalan los suelos. Estos pilares y nervios de hormigón forman la estructura del bloque principal y permiten la apertura siguiendo esa asimetría en los pisos superiores. Las paredes interiores están prefabricadas. El hueco de la escalera y el fuste del ascensor se forman mediante una trama de doce pilares de hormigón estilizados. Las puertas de la planta baja y todas las ventanas se realizaron en acero y fueron diseñadas mientras se construía la casa. Los radiadores eran de hierro fundido y las puertas de los pisos superiores eran de madera.

De todas formas, quizá lo más sobresaliente fue la precisión y el rigor matemático con el que se realizó toda la construcción, consecuencia de lo cual fue el coste final que alcanzó cifras astronómicas.

En general, Wittgenstein realizó muchas modificaciones a los planes iniciales, que no tienen un carácter funcional sino más bien estético. Wittgenstein, al contrario que en la fachada exterior, luchó por mantener un simetría interior. Se vio así en ocasiones obligado, por ejemplo, a engordar muros para lograr esta simetría interior, lo que naturalmente conlleva una pérdida de espacio.
En los materiales y decoración interior muestra la misma austeridad y simplicidad que en el exterior. Piedra artificial de color antracita brillante para los suelos, paredes enyesadas de blanco sucio o crema, cielos rasos emplastados en blanco. Las partes metálicas de las puertas se pintaron de un gris neutro o un verde grisáceo deslucido. Las dobles puertas correderas del comedor y del hueco de la escalera tenían cristales trasparentes en la cara del hall, pero en el otro lado llevaban cristales traslúcidos blancos, de tal manera, que dependiendo de qué puertas se cerraran ofrecían un distinto aspecto, abierto o reservado. Las puertas del salón eran opacas. Wittgenstein no usó molduras, rodapiés o umbrales. Las paredes, pilares y puertas se unen al suelo directamente. Así mismo los marcos de las puertas o ventanas se anclan directamente en las paredes.

Margaret temía que su mobiliario antiguo, sus copias de esculturas clásicas, sus pergaminos chinos, sus biombos y sus vitrinas que exponían objetos valiosos o curiosos contrastaran frontalmente con el estilo de la casa, pero, sin embargo, ocurrió lo contrario. La arquitectura de Wittgenstein era un contenedor perfecto para su contenido.

El diseño de las puertas de cristales y ventanas fue una obra maestra de la construcción mecánica debido a la gran rigidez que hace falta para evitar que los cristales altos y estrechos se rompan con facilidad. Los marcos de las puertas fueron construidos por secciones angulares de acero atornilladas, en donde el cristal se colocaba en la sección más estrecha que a la vez servía de cruceta diseñada preci- 
samente para este propósito. Cerrojos y picaportes se encajaban en el propio marco de la puerta.

Como es costumbre en Austria, las puertas y ventanas de las fachadas eran dobles para aislar de las frecuentes bajas temperaturas. Se abren ambas, la interior y la exterior, hacia dentro y mediante una laña montada en la puerta o ventana exterior se podían cerrar fácilmente una con otra en cualquier posición

Las ventanas tenían persianas enrollables, originariamente de metal, que transcurrían en dos carriles verticales, que las hacían invisibles cuando no se usaban; el mecanismo para subir o bajar las persianas se escondía en la pared exterior y se accionaban con cintas estrechas.

Hay tres sistemas de calefacción en la casa. En las habitaciones que tienen como piso piedra artificial hay una calefacción subterránea (una gloria). Este sistema se complementa en la Kundmanngasse mediante salidas de aire caliente en frente de las ventanas y puertas que se abren a las terrazas. Debajo de estas ventanas y puertas en el suelo existen unos canales de desagüe, la utilidad de estos rejillas pudiera ser o bien para facilitar la limpieza de las puertas o bien que formaran parte de un sistema de humidificación. Las otras habitaciones y las habitaciones superiores se calentaban mediante radiadores de agua caliente, muchos de ellos dispuestos en las esquinas, para lo cual se construyeron en dos hojas y se soldaron formando un ángulo de 90 grados. Los radiadores no se pintaron y los de la planta baja se colocaron sobre tacos de madera.
Margaret Stonborough vivió en la Kundmanngasse hasta el año 1939, año en el que emigró a los Estados Unidos. Durante la guerra, la casa sirvió como hospital militar y cuando los aliados tomaron Austria fue ocupada por el ejército ruso. El comedor se convirtió en establo para los caballos de la tropa, se instalaron estufas de carbón, cuyas salidas de humos estropearon ventanas y muros, y se dañaron armarios.

Margaret volvió y reparó su casa en 1948 viviendo en ella hasta su muerte en 1958. Posteriormente, su hijo, Thomas Stonborought, vivió en ella hasta que en 1971, debido al importante deterioro del edificio y la alta inversión que requería su reparación, dio la voz de alarma ante el inminente peligro de derribo y quiso venderla a un constructor que pretendía reformarla para abrir un hotel. Protestas de arquitectos, historiadores e intelectuales paralizaron esta operación logrando que fuera declarada monumento protegido. No fue hasta 1975 cuando el gobierno búlgaro accedió a comprarla y repararla para usarla como centro cultural de su país en Viena. Entre 1976 y 1977, la Kundmanngasse fue ampliamente reformada, aunque el resultado no fue todo lo bueno que debiera. Por otra parte, la construcción de altos edificios alrededor provocó la destrucción del jardín delantero, lo que a su vez obligó a la modificación de la entrada.

En gran medida transformada, lo importante es que aún hoy permanece ahí, mostrando la oportunidad de un talento perdido para la arquitectura, convertida en un símbolo de la Viena de principios de siglo, en un emblema 
del modernismo o del funcionalismo o de no se sabe bien qué. Lo que es claro, es que muestra el estilo singular que Wittgenstein convirtió en forma de vida.

\section{El «Estilo Wittgenstein»}

¿Puede hablarse de un estilo en el trabajo de Wittgenstein? ¿Puede adscribirse la Kundmanngasse a una tendencia arquitectónica? ¿Es una obra original? ¿Merece Wittgenstein un puesto en la historia de la arquitectura?

Evidentemente, el puesto en la historia de Wittgenstein, su gloria, está en su filosofía, pero la reflexión de interés podría residir precisamente en preguntarse cómo un hombre tan singular como nuestro filósofo fue capaz de responder a un reto, y ver este reto como un caso de otro desafío aún mayor que fue para Wittgenstein vivir, o mejor, pensar para vivir. No todo el mundo detecta la necesidad de pensar para vivir y menos aún la afronta. Si hay algo que nos permite transitar lo anecdótico, de lo importante en la vida de Wittgenstein es comprender que él fue uno de esos que se arriesgó, tal vez no vio otra posibilidad, a pensar para vivir. Sí podemos, por tanto, hablar de estilo en Wittgenstein, pero no integrado en un paradigma arquitectónico, tampoco ciertamente filosófico; sino de estilo de vida. El propio autor lo define en una anotación del día 9 de abril en sus diarios de 1930:

«Estilo es la expresión de una necesidad general humana. Esto vale tanto del estilo de escritura como del estilo de arquitectura ( $y$ de otro cualquiera).
Estilo es la necesidad general vista sub specie aeterni».

La expresión sub specie aeterni es una constante en la obra de Wittgenstein, a la vez supone el deseo inalcanzable y el límite que hay que desenmascarar. Es un concepto originario de Spinoza, con el cual distingue el verdadero conocimiento racional que nos une a la divinidad, de aquel otro representacional que no puede escapar a la imaginación. Este es el dilema del pensamiento, y por ende de la vida de Wittgenstein, como ya hemos advertido en la breve revisión de Tractatus. El hombre busca el conocimiento del mundo como totalidad, busca sentido a lo que le rodea y a lo que le pasa, es -y de este modo se nos abre la siempre posible interpretación kantiana del Tractatus, al menos- el ideal de la Razón. Y es que el hombre ha creado un ámbito de existencia desde donde se proyecta todo intento de sentido, ese ámbito de existencia es una pura ficción. Es el mundo del «deber ser». Un mundo imaginado desde donde proyectamos nuestra conducta, desde donde juzgamos nuestras acciones y la de nuestros semejantes $y$, sobre todo, desde donde planeamos nuestras intervenciones en el mundo para hacerlo más habitable. La tarea de la filosofía, desde los tiempos de Platón, es resolver los problemas de comunicación entre este mundo del deber pensado por el hombre, en gran medida gracias al lenguaje, y el mundo del ser que nos impone la vida y la muerte, el sufrimiento o el desconcierto, también la alegría y la felicidad. Ya en el Tractatus, cuando Wittgenstein llega a la filosofía, intenta hacer su contribución a la solución de 
todos los problemas filosóficos, para ello cree haber encontrado un elemento mediador que puede establecer un vínculo: la lógica y el lenguaje que la contiene. Elabora entonces su teoría del conocimiento pensando que una representación exacta del mundo contendrá el modelo adecuado de nuestro deseo, pero evidentemente, al final, comprende que eso no es así y que no podrá serlo de ninguna manera. Ahí descubre lo que de común tiene la estética, la ética, la religión o la mística: el anhelo de encontrar la manera en que debería ser el mundo para nuestra felicidad. Pero el mundo es y nuestra voluntad no lo modifica. Sin embargo, no podemos escapar a esa necesidad general, como no podemos evitar tampoco que todos nuestros actos y productos, nuestras reacciones ante el asombro y nuestros esfuerzos de conocimiento la transporten.

134 Por eso la Kundmanngasse tiene el sello de Wittgenstein. Más allá del clasicismo, del modernismo o del funcionalismo, la Kundmanngasse contiene la absoluta simplicidad, la utilidad, y la facilidad de construcción que todos los actos y reflexiones wittgenstinianas poseen.

El Tractatus muestra la desolación de aquél que confió encontrar la solución de todos los problemas filosóficos y no lo consiguió. En la obra posterior, justo cuando Wittgenstein, después de la construcción de la Kundmanngasse, vuelve a la filosofía para quedarse, inicia el filósofo una labor terapéutica contra la inquietud que puede producirnos esa necesidad general humana. Después de una asombrosa reelaboración del lenguaje como puente comunicativo entre estos dos mundo de vivencia del ser humano, concede al arte, concede en general a la visión del mundo sub specie aeterni otro papel más consolador.

En esta segunda reflexión, la tarea de la filosofía, del arte, de la ética e incluso de la ciencia es persuadirnos a contemplar el mundo de la manera más adecuada a nuestra forma de vida. El estilo conforma una forma de vida que nos resulta útil aunque deje el mundo como está. De nuevo encontramos en sus lecciones de estética pasajes sumamente representativos de la filosofía wittgensteiniana

34. Tienen forma de persuasión aquellas proposiciones en particular que dicen: «Esto es realmente esto»: se les ha persuadido a no prestar atención a determinadas diferencias.

Por eso también en sus Aforismos [MS 109 28, 22.8.1930] encontramos el nuevo cometido que concede al arte:

«Pero ahora me parece que a parte del trabajo del artista hay otro: aprehender el mundo sub specie aeterni. Es -creo- el camino del pensamiento que, por así decirlo, vuela sobre el mundo y lo deja tal y como está, -contemplándolo desde arriba en el vuelo-.»

Ya no necesitamos una descripción exacta, no es posible; pero sí podemos habitar allí donde la escalera nos haya conducido, incluso podemos invitar a más gente pues ya es compartible y comunicable. Toda la filosofía de Wittgenstein podría entonces resumirse en la siguiente propuesta persuasiva con la que termina sus lecciones de Estética:

41. Todo lo que estamos haciendo es cambiar el estilo de pensar y todo lo que yo estoy haciendo es 
cambiar el estilo de pensar y persuadir a la gente para que cambie su estilo de pensar.

Naturalmente, esto suena a declaración fundacional de la posmodernidad, pero necesitaremos medio siglo aún para persuadirnos y ver la alegría que -creo- para Wittgenstein tuvo que representar la revisión de su pensamiento.

¿Y esta concepción general del estilo, cómo se vierte en la Kundmanngasse?

Podríamos calificar el diseño originario de Engelmann de la Kundmanngasse como de clasicista. Encontramos los principios característicos de la escuela de Loos: masas definidas rígidamente, claridad volumétrica y una aplicación simplificada y reconfigurada del ornamento clásico. Los elementos modernos según los inicios del siglo podemos encontrarlos en la disposición asimétrica de los volúmenes cúbicos y la asimetría correspondiente de la planta principal de la casa. Sin embargo, el desagrado que le producen a Wittgenstein algunos de los aspectos del diseño inicial, le llevará a hacer evolucionar el estilo hacia su propio clasicismo «auténticamente moderno». La regla estética que subyace a la reelaboración y al estilo wittgenstiniano es, naturalmente, la simplicidad.

Esta simplicidad se manifiesta en el énfasis que pone el filósofo en la claridad y definición volumétrica. Elimina todo ornamento clásico, reduciendo la arquitectura a líneas rectas imperturbables que corren paralelas o perpendiculares entre sí, a la intersección de los planos que crean las líneas, a la simetría y la proporción, a la pura percepción de la pro- fundidad o de su carencia y al efecto puro de la luz y la sombra. La anotación de Wittgenstein lo expresa más rotundamente: «Mi ideal es un cierto equilibrio. Un templo provee un escenario para las pasiones sin interferir en ellas». También nos da que pensar la anotación en sus diarios del 24 de abril de 1931:

«El secreto del dar dimensiones a un sillón o a una casa es que ello cambia la concepción del objeto. Lo hago más corto y parece una continuación de esta parte, lo hago más largo y parece una parte completamente independiente. Lo hago más sólido y lo demás parece apoyarse en ello, lo hago más endeble y parece pender de lo demás, etc.

Lo importante no es propiamente la diferencia gradual de la longitud, sino lo cualitativo de la concepción.»

Apoyándose en la modernas técnicas de construcción, puntales y vigas de hormigón, logra marcos estructurales internos diáfanos, tejados y cubiertas con los mínimos filos; los paneles prefabricados le permiten particiones finas de las paredes. Naturalmente en estos rasgos estructurales modernos conecta el trabajo de Wittgenstein con el de Adolf Loos y sus alumnos Engelmann y Groag, pero también proyecta la tradición arquitectónica del barroco clasicista vienés de los Palacios tal y como lo desarrollara su mejor representante, Johann Bernand Fischer von Erlach, a quien Wittgenstein admiraba. Aunque evidentemente purifica todo lo estrictamente barroco: elimina el ornamento, disminuye la profundidad en el portal e incrementa la organización simétrica tradicional. 
Finalmente, tal vez enlazando con el clasicismo grecoromano, encontramos la introducción de los elementos mecánicos en el conjunto, puertas y ventanas y sus mecanismos de cierre o apertura, el ascensor, el sistema de calefacción y naturalmente toda la naciente instalación eléctrica.

La propia monumentalidad del edificio, su aspecto desmaterializado, rompe con la arquitectura moderna del momento, que al igual que la época que estaba viviendo no le gustaba a Wittgenstein, y lo vincula más con esa tradicional concepción monumental del espacio que no quiere establecer conexiones entre el edificio y su función, o que evita atender al medio arquitectónico circundante.

La arquitectura, pensaba, debe inmortalizar y glorificar algo, y si no hay nada que glorificar, evidentemente, no puede haber arquitectura. La idea, que llega hasta nuestros días, de que vivimos un tiempo de progreso y que el progreso consiste en incrementar la complejidad, le preocupaba a Wittgenstein en la medida en que la claridad como valor sólo servía como medio para hacer construcciones cada vez más complicadas. Sin embargo, para él la claridad era un fin en sí mismo, como probablemente lo era también en su quehacer filosófico.

«No me interesa erigir un edificio, sino representarme perspicuamente a mí mismo los fundamentos de todo edificio posible», expresaba en el borrador de un prólogo a un manuscrito de 1930. Así es como debemos entender la idea de claridad en su pensamiento. Esta idea va a ir tomando un papel fundamental en su filosofía posterior en la noción que, a menudo, se ha traducido como representación perspicua. La filosofía posterior, cuando Wittgenstein se hace un profesional de la misma, se va a centrar en invertir esta relación. Por una parte, analizar el progreso que ha de llevarnos a una representación perspicua; por la otra, en comprender las consecuencias de su obtención. Si el Tractatus fue un edificio de pensamiento, la obra posterior que cristaliza en las Investigaciones Filosóficas va a consistir precisamente en la búsqueda de los fundamentos de todo edificio posible, para lo cual tendrá primero que aprender a habitar entre las ruinas.

En fin, nunca Wittgenstein gustó de la corbata y casi nunca la llevaba, posiblemente este hecho en la Viena de comienzos de siglo sea más característico que todas las relaciones arquitectónicas que seamos capaces de traer a colación. Desde algún punto de vista quizá eso pueda ser visto como un síntoma de transgresión, desde otro, efectivamente, como uno más claro de reacción. Al final, lo mejor sería renunciar a la clasificación que toda persona que piensa para vivir imposibilita, pues normalmente son éstas quienes crean las categorías o transfiguran las antiguas para producir otras nuevas. Atendiendo a esto podemos interpretar lo que escribió Wittgenstein alrededor del año 1932 y que queda recogido en el capítulo titulado Filosofía del manuscrito que se conoce como «Big Typescript» [TS 213].

«El trabajo en Filosofía -como a menudo en la arquitectura- es realmente más el trabajo en uno mismo. En la propia manera de pen- 
sar. En la manera en que uno ve las cosas. (Y en lo que se requiere de ellas).»

\section{El Pensamiento como Edificio}

A Partir de 1929, Wittgenstein vuelve a Cambridge y con ello vuelve a la Filosofía, esta vez para quedarse. La inquietudes que, desde el abandono de su puesto como maestro de escuela, le suscitaban tener que elegir la profesión adecuada para una vida honesta y digna, se resuelven dedicándose a la Filosofía, aunque estas inquietudes, para él y en su juicio a los demás, le acompañarán toda la vida.

Si en el Tractatus declaraba que todos los problemas filosóficos han quedado resueltos y no requieren mayor dedicación, ¿cómo es que ahora se ve en la obligación de retomarlos y ofrecer respuestas distintas?

El Tractatus edificaba compactamente, sin fisuras, una teoría de la representación exacta del mundo, pero ya en sus puntos finales Wittgenstein descubría que esa representación no nos servía para vivir. Seguíamos encerrados en los límites del edificio construido y nadie podía entrar, ni nosotros salir. Esto no podía ser una respuesta definitiva a nuestras preocupaciones sobre la vida buena, tampoco al posible uso que podemos hacer del pensamiento para llevarla a cabo.

En el prologo a las Investigaciones Filosóficas, su segunda, aunque ya póstuma, obra, que demarca a un primer de un segundo Wittgenstein, como ya se ha hecho tópico entre sus comentaristas -quizá sin razón-, nos expresa el reconocimiento de los errores del
Tractatus y nos sugiere la idea de leer juntos sus viejos pensamientos con los nuevos, pues -considera- existe un trasfondo común.

Las Investigaciones no son desde luego un ejercicio de arquitectura. Al contrario, como el mismo Wittgenstein explica también en el prólogo, constituyen a lo sumo un álbum, porque:

«Tras varios intentos desafortunados de ensamblar mis resultados en una totalidad semejante, me di cuenta de que eso nunca me saldría bien. Que lo mejor que yo podría escribir siempre se quedaría sólo en anotaciones filosóficas... Las anotaciones filosóficas de este libro son como un conjunto de bosquejos de paisajes que han resultado de estos largos y enmarañados viajes.»

Visto de esta manera, si Wittgenstein hubiera tenido que afrontar un nuevo trabajo de edificación, ¿qué casa habría hecho? La reflexión Wittgenstiniana a partir del año 30 parece fundamentalmente una reflexión cuidadosa y curiosa del proceso que la construcción de un edificio exige. El Tractatus, como la Kundmanngasse, se levantan como obras terminadas, como representaciones exactas del mundo o del plano que lo diseña. Ahora la reflexión transcurre deteniéndose en las labores de derribo, desescombro, topografía, cimentación, levantamiento de planta, cubierta, etc. Parece como si Wittgenstein quisiera, investigando el proceso, comprender el resultado. Parece como si viviendo pudiera darse sentido a la vida toda. Entender los mecanismos de la vida humana para llevarla adelante. ¿Es que no basta ya tener 
el plano por adelantado para edificar correctamente? ¿Es que las representaciones exactas no pueden alumbrar nuestra existencia diaria? Wittgenstein parece comprender que la articulación, en un grado arbitrario de detalle, de pensamiento y acción, de los hechos y los valores, constituye el trabajo filosófico. Pero, ¿por qué es incapaz de tal articulación? ¿Por qué hay que acostumbrarse a vivir ahora en las ruinas de las casas que habitamos antes?

«Es verdad que se ha de poder vivir también en los escombros de las casas en las que se acostumbra a vivir. Pero es difícil. Se había tomado el gusto al calor y comodidad de las habitaciones, aunque no se supiera. Pero ahora, cuando uno deambula por las ruinas, se sabe.

Se sabe que ahora sólo puede dar calor el espíritu y que no se está acostumbrado en absoluto a dejarse calentar por el espíritu.» (Diarios 1930-32/1936-37, Anotación del 31-10-31)

El proceso de este descubrimiento es complejo, lo primero es comprender, y aterrorizarse, que nuestras representaciones dejan el mundo como está.

En los $\S \S 252-271$ de los últimos escritos sobre Filosofía de la Psicología de los años 1948-49 encontramos el siguiente análisis del concepto de la simulación que vamos a emplear para delinear brevemente esta segunda navegación filosófica. Lo primero que nos sorprende es la siguiente secuencia:

$\S 257$ Que significa esto: «Toda conducta podría ser, en teoría, simulación».
$\S 258$ Seguramente tiene que significar: el concepto simulación lo permite.

$\S 259$ Y eso significa: Si experimento esto, aquello y esto otro, tal vez diría que esto es (fue) simulación. (Geometría Euclidea).

Pero, ¿dónde está escrito que diríamos esto?; o, ¿de dónde lo deduzco?

'En la medida en que ese concepto está determinado, también lo permite'.

Wittgenstein parece descubrir con asombro que la idea representacionalista, en la que había basado el intento de respuesta a los problemas que la filosofía y la vida nos plantea, está infundada, pues parece que el conocimiento humano, que el concepto de simulación resume, sólo puede erigirse sobre el suelo firme que él mismo construye.

Si se quiere, en nuestra gramática existe un concepto, el de simulación, capaz de poner en cuestión cualquier otro, pero también se constituye en condición de posibilidad del conceptualizar, del representar.

La reflexión wittgensteniana pretende encontrar el fundamento de que 'el concepto lo permite' y a la vez limitar su alcance, al contextualizar ese fundamento a ciertas ocasiones de uso. Siguiendo el texto, Wittgenstein se muestra desconfiado e inseguro ante las posibilidades del concepto. Siente la necesidad de limitar estas posibilidades, pero debe encontrar un asentamiento desde donde poner un cerco. Así:

$\S 268$ ¿No podría alguien mostrar lo que entiende por 'simulación' inventando historias en las que 
sucedieran simulaciones? Para desarrollar el concepto de simulación inventa siempre historias cada vez más complicadas. Por ejemplo, lo que parece una confesión sólo es continua simulación; lo que parece simulación es sólo fachada para esconder el propio fingir, etc.

Luego el concepto descansa en un tipo de historia.

\section{o también:}

§ 263 Una obra dramática, por ejemplo, te enseña cómo son los casos de simulación.

Efectivamente, el concepto descansa en un tipo de historia, en una intención. Nuestros recursos de pensamiento sólo tienen eficacia en una necesidad vital. Nuestro lenguaje, por ejemplo, se articula en juegos de lenguaje que forman parte de una actividad o de una forma de vida. Ya no tiene sentido plantearse el lenguaje como figura de la realidad, pues la realidad, como al solipsista, no se nos enfrenta.

Abandonada la idea de un lenguaje ideal, privilegiado, de alguna manera privado o al menos único; abandonada la idea de que accedemos al mundo por el lenguaje que lo representa; entramos en un momento de indeterminación. El lenguaje se multiplica, ya no hay un único lenguaje que yo pueda entender (T. 5.62), aquél que cifra la lógica del mundo, sino que el lenguaje es constantemente recreado según reglas. Creado y recreado dependiendo de nuestras intenciones. Si nuestro lenguaje ya no significa al mundo, si el significado de nuestras palabras no son los objetos del mundo, ¿qué es, entonces, el significado de una palabra?
Con esta misma pregunta se abre el Cuaderno Azul (1930). Una vez que se formula tal pregunta se nos produce un espasmo mental, que nos fuerza a responder que el significado es esto o aquello. Pero, a la vez, nos damos cuenta de que somos incapaces de señalar o indicar nada en concreto que valga como respuesta. Wittgenstein nos recomienda que nos fijemos en situaciones concretas. Por ejemplo:

«Imaginemos un lenguaje entre el albañil A y su peón B. El lenguaje consta de las palabras «cubo», «ladrillo», «loseta», «columna». La intención es que el peón le de al albañil los materiales que necesita.

A grita una de estas palabras, tras ello B trae una piedra de una forma determinada.

Imaginemos ahora una sociedad en la que éste sea el único lenguaje. En ella -nos dice Wittgenstein- el niño aprende el lenguaje de los mayores entrenándose en su uso. En el uso real del lenguaje $A$ grita una palabra como orden y B actúa de acuerdo a ella.» (Cfr. Cuaderno Marrón §1).

Cuando preguntamos por el significado de una palabra, inmediatamente tendemos a pensarlo como un acto mental que de un modo u otro se forma la persona. De lo visto en el ejemplo que nos propone Wittgenstein el resultado es muy otro. La idea de significado que nos hacemos cuando nos vemos metidos en un lenguaje como el descrito responde mejor al papel que juegan nuestros signos en un sistema de lenguaje. Esto es, al uso que desempeñan nuestras palabras en ciertos contextos. Es más, la idea resultante es que las experiencias mentales que acompañan al uso de un signo están causadas por 
nuestro uso del signo en un sistema de lenguaje particular.

De alguna manera, cada tipo de palabra, nombre, número, nombre propio, demostrativo, etc., conlleva un modo de aprendizaje distinto. Para unos parecerá que alcanzamos el significado mediante una definición ostensiva, mediante un señalar a un referente, para otros en un acto mental. Pero sea cual sea el papel de la demostración (señalar, pronunciar) de nuestro lenguaje imaginado no establece la diferencia en el aprendizaje de diversos tipos de palabras, sino en el papel que juega en el entrenamiento y en el uso que se hace de las palabras en la práctica de la comunicación por medio de ese lenguaje. El señalar ocurre en el uso de la palabras.

El significado de las palabras reside en el uso que hacemos de ellas en ciertos contextos. A partir de ahora el uso pasa a ser el criterio del significado de las palabras. El significado de una palabra no le es conferido por una ceremonia de etiquetado, sino que es determinado por las reglas de uso de esa palabra. El uso de una palabra viene dado por los criterios que justifican su aplicación en un sistema de lenguaje dado.

Pero, qué es un sistema de lenguaje. ¿Es posible que la misma palabra desempeñe diversos usos -tenga diversos significados- dependiendo del sistema donde se usa? Sí, y es más, contra el único lenguaje del Tractatus, el lenguaje referencial, aparece ahora una pluralidad de usos, no sólo de las palabras, sino también del mismo lenguaje.

Un juego de lenguaje es el lenguaje imaginado del ejemplo anterior. Podemos pensarlo como un juego por medio del cual el niño aprende su lenguaje nativo. El término «juego de lenguaje» es empleado para dar importancia al hecho de que hablar un lenguaje es parte de una actividad, o de una forma de vida. Hay miles de juegos de lenguaje, obsérvense los siguientes ejemplos que ofrece Wittgenstein:

\section{Dar ordenes, y obedecerlas}

Describir la apariencia de un objeto, o dar sus medidas.

Construir un objeto desde una descripción Narrar un acontecimiento

Especular sobre un acontecimiento

Formar y probar una hipótesis... (PU §23)

Los juegos del lenguaje son el lugar donde hay que investigar el significado de las palabras. En ellos las palabras son usadas. El lenguaje es un instrumento que sirve para muchas cosas, es parte de una actividad. Los juegos del lenguaje son tantos como actividades humanas puedan concebirse, por eso su definición es y será incompleta. No tienen entre ellos tampoco una esencia común, interactúan y se interfieren unos con otros. Todo lo más, su relación tiene un «aire de familia». Pero incluso dentro de un mismo juego determinado, por ejemplo «Esperar a alguien a tomar el té», hay infinitos modos de afrontarlo. Cada modo determina una expectativa en nuestra comunicación. Todos los casos de expectación forman una familia y tienen «aires de familia» que no están claramente definidos.

Pero la propia capacidad constructiva del pensamiento y del lenguaje nos lleva a crear un edificio independiente del mundo en donde sólo habita el pensamiento y el lenguaje mismo. $\mathrm{O}$, tal vez, el propio poder constructivo 
del lenguaje le permite crearse un mundo para sí que tiende a mostrarse como lo que realmente es y que nos engaña muy a menudo. A ese poder constructivo lo denomina Wittgenstein «lo gramatical» y a su creación Gramática.

Los problemas filosóficos surgen ahora de malentendidos lingüísticos:

«en vez de 'no se puede' di: 'no hay en este juego'. En vez de 'no se puede enrocar en las damas' - 'no hay enroque en las damas'...»

El problema de la Metafísica es que confunde o bien un juego con otro o bien considera un juego del lenguaje como el único existente. El problema del metafísico es que sus proposiciones son proposiciones gramaticales -aquéllas que versan sobre el uso o el significado de las palabras- revestidas como proposiciones empíricas, confundiendo así dos juegos lingüísticos. El criterio que debemos seguir ahora es preguntar si las palabras se usan de tal y tal modo en el juego donde se hallan incluidas. Si no se usa como el juego exige habrá que devolverlas a su juego de origen. Despejamos así los errores

Ahora, Wittgenstein, sospechando que la relación entre gramática y uso no se articula linealmente, sino que el lenguaje recorre caminos diversos hasta conformar juegos que se distancian entre sí posteriormente -como mucho mantienen ese «aire de familia»-, le concede al lenguaje el papel de una herramienta $y$, como tal, un medio para un fin.

Por eso termina el parágrafo 269 preguntándose retóricamente:
«... Por tanto, ¿es la intención el fundamento originario? Y, ¿cómo podemos descubrirla en la historia?

A la vez que quiere parar el constante proceso de simulaciones, reconoce las dificultades de descubrirlo dentro de las historias. Reconoce que el proceso de invocación de una intención puede sufrir la misma explosión combinatoria que el de simulación. Pues la intención puede llamar a otra intención indefinidamente. Hay que recurrir a algo externo, plantearse, ¿qué significa aquí 'comprender'? ( $\$ 266$ ) y reconocer que sólo en el resultado hallaremos la respuesta y partiendo del resultado reconstruir la secuencia hasta remontar a la intención originaria. Pero este recurso externo nos lleva a la exigencia de la interpretación.

El Wittgenstein que ha rechazado el solipsismo del Tractatus por pensar que su descripción del conocimiento le conduce a la construcción de un edificio sin salida, a un proceso metafórico sin fin, porque su origen no pertenece al mundo, pretende ahora limitarlo apelando a un proceso de articulación entre dos polos, la gramática y el uso; haciendo descender la semejanza a algo que convencionalmente se establece conforme se usa. Por eso el interés en encontrar la representación perspicua, por eso el deseo en representarse perspicuamente a sí mismo los fundamentos de todo edificio posible. La noción de representación perspicua cobra en la segunda reflexión wittgensteiniana una importancia capital, pues se va a convertir en el punto medio en donde el pensamiento se detiene para usarlo en la vida, para convertirse en actividad. 
Así lo expresa en el § 122 de la Investigaciones, aunque el origen de este pasaje ya lo encontramos en escritos del año 1930:

122. Una fuente principal de nuestra falta de comprensión es que no vemos perspicuamente (sinópticamente, panorámicamente, claramente -son otras traducciones posibles-) el uso de nuestras palabras -A nuestra gramática le falta visión perspicua. $-\mathrm{La}$ representación perspicua produce la comprensión que consiste en 'ver conexiones'. De ahí la importancia de encontrar y de inventar casos intermedios. El concepto de representación perspicua es de fundamental significación para nosotros. Designa nuestra forma de representación, el modo en que vemos las cosas. (¿Es esto una 'Weltanschauung'?).

Efectivamente comprendemos estableciendo conexiones, inventando casos intermedios, creando metáforas. Wittgenstein se encuentra en el apuro de tener que renunciar al caso límite de la exactitud, y debe cuidarse de no forzar la analogía. Esta es la idea de claridad que alumbra su pensamiento y su vida. No todo edificio tendrá que ser una fortaleza inexpugnable que se convierta en cárcel de uno mismo, ni ruina que nos fuerce a calentarnos con nuestro espíritu desacostumbrado. Para comprender las cosas necesitamos saber lo que requerimos de ellas. Para construir edificios tendremos también que saber lo que queremos hacer con ellos. Por eso «Tampoco es posible que todo comportamiento sea simulación bajo toda circunstancia.» ( $\$ 253)$

§ 255 También podíamos decir: El concepto simulación tiene que ver con un problema práctico. Y el límite confuso del concepto no cambia con ello.

§ 262 Luego, no todas las conductas pueden ser, en todas las circunstancias, simulación.

(Al 'fingir' pertenece la ocasión, el motivo, etc.)
Pero, ¿por qué Wittgenstein, que ha reelaborado con precisión la idea del lenguaje, que ha comprendido que nuestro conocimiento está sometido a nuestra intención, que está obligado a saber lo que requerimos de las cosas, no puede terminar el nuevo edificio de su pensamiento?

Seguramente, al dedicarse a comprender el proceso de la edificación, al descubrir que hay muchas maneras de hacer las cosas con los mismos recursos, al persuadirnos que hay numerosos estilos de pensar y de vivir, al buscar la claridad como valor y saber que se puede convertir en hecho, no tuvo la intención de una nueva edificación. Aprendió a calentarse con su espíritu y renunció a establecerlo como obligación. Porque:

«En la vida, como en la filosofía, nos seducen aparentes analogías (con lo que otro hace o puede hacer). Y también aquí hay un solo medio contra esa seducción: hacer caso a las suaves voces que nos dicen que aquí las cosas no son como allí» (Diarios 1930-32/1936-37, Anotación del 6-5-31)

En el frágil equilibrio de los juegos del lenguaje, de los casos intermedios, de las analogías por las que como funambulistas nos movemos, encontramos la posibilidad de habitar y comprender un mundo que siempre ha de quedarse como está. Podemos tirar la escalera que nos ha permitido elevarnos hasta el cable, pero la vida comienza de nuevo ahí donde el balanceo nos expone a un riesgo.

Wittgenstein edificó un estilo de pensamiento y también construyó una casa. Para él Arquitectura y Filosofía eran solamente lugares donde arriesgar su vida ${ }^{4}$. 


\section{BIBLIOGRAFÍA}

Amendolagine, F. \& Cacciari, M. (1975): La casa di Wittgenstein. ln: E. Amendolagine a M. Cacciari, OIKOS da Loos a Wittgenstein. Rome: Officina Edizioni.

Beek, van de, J. 1987. Adolf Loos - Patronen stadswoonhuizen. In: M. Risselada ed., Raumplan versus plan libre. Delft: Delft University Press.

Bock, M. (1977): Vom Monument zur Städteplanung: Das Neue Bauen. In: Tendenzen der Zwanziger Jahre. Exhibition cataloque. Berlin: Reimer.

Bouveresse, J. (1973): Wittgenstein: La rime et la raison. Paris: Éditions Mínuit.

Bouveresse, J. (1986): Wittgenstein et l'architecture. In: Vienne. l'Apocalypse joyeuse. Exhibition catalogue. París: Centre Pompidou.

Eccles, W. (1963): Sorne letters of Ludwig Wittgenstein. In: Hermathena, 97, pp. 57-65.

Eggert, K. (1976): Der Wohnbau der Wiener Ringstrasse im Historismus 1855-1896, Wiesbaden: Steiner.

Engelmann, P. (1911): [Das Haus auf dem Michaelerplatz]. In: Die Fackel, 317/318, 28. February, p. 18.

- (1913): Studie zu einer Villa. In: Der Architekt, XIX, plate 148 .

- (1929): see: Ostdeutsche Bauzeitung, 27, p. 654.

- (1946): Adolf Loos. Tel Aviv: Paul Engelmann. Facsirnile edition 1984, Vienna: Architektur- und Baufachverlag.

- (1948): Ludwig Wittgenstein. Tel Aviv: Paul Engelrnann.

- (1967): Letters from Ludwig Wittgenstein. With a Memoir Translated by L. Furtmüller. Oxford: Basil Blackwell.

- (1967): Dem Andenken an Karl Kraus. Edited by Elazar Benyoetz. Vienna: Kerry.

Fann, K. T. (ed.) (1967): Ludwig Wittgenstein. The Man and His Philosophy New York: Dell.

Flammersfeld, M.-L (1974): Het sluitwerk van Ludwig Wittgenstein. In: De Revisor, 8, pp. 17-2l.

Frank, J. (1931): Architektur als Symbol, Viena: Schroll.

Frey, D. (1923): Johann Bernhard Fischer von Erlach. Vienna: Hölzel.

Gasking, D. T. A. / Jackson, A. C. (1951): Ludwig Wittgenstein. In: The Australasian Journal of Philosophy, XXIX, pp. 234-248.

Gebauer, G., Grünenwald, A., Ohme, R., Rentschler, L, Sperling, Th., Uhl, 0. (1982): Wien, Kundmanngasse 19. Munich: Wilhelm Fink.

Giacornini, U. (1965): Un'opera architettonica di Wittgenstein. In: Aut, aut, May, pp. 88-92.

Graf, O. A. (1985): Otto Wagner. Das werk des Architekten. 2 vols. Vienna: Böhlau.

Gravagnuolo, 8. (1981): Adolf Loos. Milano: Idea. Engl. (1982). Translated by C.H. Evans. Milano: Idea and Löcker.
Grirnschitz, 8. (1944): Wiener Barockpaläste. Vienna: Wiener Verlag.

Gropius, W. (1913): Die Entwicklung moderner Industriebaukunst. In: Jahrbuch des Deutschen Werkbundes. Berlin.

Hänsel, L.(1951): Ludwig Wittgenstein (1889-1951). In: Wissenschaft \& Weltbild, 4, p. 274-277.

Hård af Segerstad, U. (1970): Huset som Wittgenstein byggde. In: Svenska Dagbladet, 6 February, p. 5.

Hayek, F. A. (1953): Sketch of a Biography of Ludwig Wittgenstein. Written in 1953 for private circulation by FA. Hayek, with some later corrections and insertions. Unpublished manuscript.

Hermans, W. F. (1968): Wittgenstein en Wittgensteinboeken. In: Literair Paspoort, 23, 222, pp. 181-189.

Hermans, W.F. (1971): Van Wittgenstein tot Weinreb. Amsterdam: De Bezige Bij.

Hoffmann, W. (1969): Ludwig Wittgenstein, ein Philosoph als Architekt. In: Bau, 1, pp. 3-8.

Indiana, G. (1985): Ludwig Wittgenstein, Architect. In: Art in America, January, pp. 112-133.

Janik, A. (1985): Essays on Wittgenstein and Weininger. Amsterdam: Rodopi.

Janik, A. / Toulmin, S. (1973): Wittgensteins Vienna. New York: Simon and Schuster. (trad. al Castellano en Taurus, 1983)

Kapfinger, 0. (1984): Haus Wittgenstein. Eine Dokumentation. Vienna: Kulturabteilung der Botschaft der Volksrepublik Bulgarien.

- (1989): Kein Haus der Moderne. In: M. Huter ed. Wittgenstein. Biographie, Philosophie, Praxis. Vienna: Wiener Secession.

Kapfinger, 0. / Leitner, B. (ed.) (1989): WitrgensteinHaus. Ein Pressespiegel Juni/iuli/August 1971. Vienna: Wiener Secession.

- (1972): Die Steine der Wiener Ringstrasse. Wiesbaden: Steiner.

Kraft, V. (1951): Ludwig Wittgenstein. ln: Wiener Zeitschrift für Philosophie / Psychologie/ Pädagogik, 3, pp. 161-163.

Kraft, W. (1961): Ludwig Wittgenstein und Karl Kraus. In: Neue Rundschou, LXXIU/4, pp. 812-844.

Kulka, H. (1931): Adolf Loos. Vienna: Schroll. Republished in $1979 / 1985$ by Löcker, Vienna.

Kurrent, F. / Spalt, J. (1970): Unbekanntes von Adolf Loas. 1n: Bauforum, 3, 21, pp. 29-48.

Lee, H. D. P. (1979): Wittgenstein 1921-1931. In: Philosophy, 54, pp. 211-220.

Lee, H. D. P. (ed.) (1980): Wittgensteins Lectures, Cambridge 1930-1932. From the Notes of John King and Desmond Lee. Chicago: University of Chicago Press.

Leitner, B. (1970): Wittgensteins Architecture. In: Art Forum, February, pp. 59-61. 
- (1973): The Architecture of Ludwig Wittgenstein. A Documentation. Halifax: Nova Scotia College of Design (New York, 1976: New York University Press).

Leitner, B. (1985): Zur Architektur von Ludwig Wittgenstein. In: Parnass, 2, pp. 24-31.

- (1989): Das Haus in Bewegung. In: M. Huter ed. Wittgenstein. Biographie, Philosophie, Praxis. Vienna: Wiener Secession.

Loos, A. (1908): Ornamentund Verbrechen. Vienna.

- (1910): Architektur. Vienna.

- (1911): Mein Haus am Michaelerplatz. 1n: Parnass Sonderheft, 2.

- (1912): Verzeichnisder Vorlesungen an der Bauschule Adolf Loos. Vienna.

- (1913) Meine Bauschule. In: DerArchitekt, XIX, pp. 69-76.

- (1919): Richtlinien für ein Kunstamt. Vienna: Lanyi.

- (1921): Ins Leere Gesprochen. 1897-1900. Paris: Georges Crés. 2. revised ed. (1932) Innsbruck: Brenner. Reprint of the Ist ed. (1981) Vienna: Prachner.

- (1931): Trotzdem 1900-1930. Innsbruck: Brenner. Reprint (1982) Vienna.

- 1962. Säimtliche Schriften. Band I. Edited by Franz Glück. Vienna/Munich: Herold.

- (1983): Die Potemkinsche Stadt. Verschollene Schriften I897-1933. Edited by Adolf Opel. Vienna: Prachner.

Malcolm, N. (1984/1958): Ludwig Wittgenstein. A Memoir. With a biagraphical sketch by G.H. von Wright. Second edition with Wittgenstein's letters to Malcolm. 2nd revised edition. Oxford: Oxford University Press.

Mays, W. (1955): Note on Wittgenstein's Manchester period. In: Mind, IXIV 1955, pp. 247-248.

- (1967): Recollections of Wittgenstein. In: K.T. Fann ed, Ludwig Wittgenstein. The Man and His Philosophy New York: Dell.

McGuinness, B. F (1966): The mysticism of the Tractatus. In: Philosophical Review, 75, pp. 305-328.

- (1985): Ornament und Askese in der Denkweise Wittgensteins. In: A. Pfabigan ed., Ornamentund und Askese im Zeitgeist des Wien der Jahrhundertwende. Vienna: Brandstätter.

McGuinness, B. F. (1988): Wittgenstein. A Life. London: Duckworth.

Methlagl, W. (1969): Erläuterungen zur Beziehung zwischen Ludwig Wittgenstein und Ludwig von Ficker. In: G.H. von Wright ed., Briefe an Ludwig von Ficker. Brenner Studien 1. Salzburg: Müller.

Micheletti, M. (1967): Lo schopenhauerismo di Wittgenstein. Balogna: Zanichelli.

Monk, R. (1990): Ludwig Wittgenstein. The Duty of Genius. London: Janathan Cape.

Mulder, H. L. (1968): Wissenschaftliche Weltauffasung. Der Wiener Kreis. In: Journal of the History of Philasophy, 6, pp. 386-390.

Nedo, M. (1989a): Familienähnlichkeit, Philosophie und Praxis. In: M. Huter ed., Wittgenstein. Biographie, Philosophie, Praxis. Vienna: Wiener Secession.
Nedo, M. (1989b): Eme medizinisch-technische Apparatur. In: Huter ed., Wittgenstein. Biographie, Philosophie, Praxis. Vienna:Wiener Secession.

Nedo, M. / Ranchetti, M. (1983): Wittgenstein. Sein Leben in Bildern und Texten. Frankfurt/Main: Suhrkamp.

Parak, F. (1978): Wittgenstein prigioniero a Cassino. Roma: Armando Armando.

Plaisier, P. (1987): De leerlingen van Adolf Loas. Delft: Delft University Press.

Plattus, A. (1974): On Bernhard Leitner's The Architecture of Ludwig Wittgenstein: A Documentation In: Oppositions, 3, pp.107-109.

Rhees, R. (ed.) (1984): Recollections of Wittgenstein. Oxford: Oxford University Press.

Rukschcio, B. / Schachel, R. (1982): Adolf Loos. Leben und Werk. Salzburg: Residenz.

Safran, Y. (1983): The curvature of the spine: Kraus, Laos and Wittgenstein. In: 9H, 4, pp. 17-22.

Scheu, R. (1909): Adolf Loos. In: Die Fackel, 283/284, 26 Juni, pp. 25-37.

Sedlmayr, H. (1984/1959): Allegorie und Architektur. In: M. Warnke ed., PalitischeArchitektur in Europa vam Mittelalter bis heute. Cologne: Durnont

Sekler, E. F. (1971): Zur Wertung des Hauses Wien III. Kundmanngasse 19. (Villa Stonborough - Wittgenstein) Unpublished expert opinion cornmissioned by the Bundesdenkmalamt, Vienna.

Sjögren, C. (1989): Die Familie. In: M. Huter ed., Wittgenstein. Biographie, Philosophie, Praxis. Viena: Wiener Secession.

Slapeta, V. (1978): Paul Engelmann und Jacques Groag, die Olmützer Schüler von Adolf Loas. In: Bauwelt, 40, pp. 1494-1501.

Tranøy, K. E. (1976): Wittgenstein in Cambridge 19491951: Some personal recollections. In: Acta Philasaphica Fennica, 28, pp. 11-22.

Turnovsky, J. (1987): Die Poetik eines Mauervarsprungs. Braunschweig/Wiesbaden: Vieweg.

Wagner, 0. (1895): Moderne Architektur. Vienna.

— (vol. 1:1889, 2:1897, 3:1906, 4:1922): Einige Skizzen. Projekte und ausgeführte Bauwerke. Vienna. Reprint (1987): Otto Wagner. Tübingen: Wasmuth.

Waismann, F. (1967): Ludwig Wittgenstein und der Wiener Kreis. Oxford: Basil Blackwell.

Walden, G. (1989): Fotografie als Beschreibung. In: M. Huter ed., Wittgenstein. Biographie, Philosophie, Praxis. Vienna: Wiener Secession.

Wittgenstein, H.: Familienerinnerungen. Unpublished manuscript.

Wittgenstein, L. (1922). Tractatus Logico-Philosophicus. (T) Ed. por G. E. M. Ascombe y Rush Rhees, Routledge \& Kegan Paul, Ltd., Londres. Trad.: J. Muñoz e I. Reguera, Alianza, Madrid, 1987.

- (1953). Philosophische Untersuchungen. (PU) Ed. Bilingüe de G. E. M. Ascombe y R. Rhees, Basil Blackwell, Londres. Trad.: A. García Suarez y Uli- 
ses Moulines. Crítica, UNAM. Barcelona-México, 1988.

- (1958). The Blue and Brown Books, Basil Blackwell, Oxford. Trad.: F. García Guillén. Los Cuadarnos Azul y Marrón. Tecnos, Madrid, 1968

- (1961). Notebook (1914-1916). Basil Blackwell, Oxford. Trad.: J. Muñoz e I. Reguera. Diario Filosófico (1914-1916), Ariel, Barcelona, 1982.

- (1965). Wittgenstein's Lecture on Ethics. (CE) The Philosophical Review. Trad.: Fina Birulés. Conferencia sobre Etica. Paidos/ I.C.E.-U.A.B. Barcelona, 1989

- (1967). Bemerkugen über Frazers The Golden Bough. Synthese, XVII. Trad.: J. Sádaba y J. L. Velázquez. Observaciones sobre la rama Dorada de Frazer, Tecnos, Madrid, 1992.

- (1968). Wittgenstein's Notes for Lecture on "Private Experience» and "Sense Data» (Ed.: R.Rhees), The Philosophical Review 77, pp. 217-320.

- (1969): Briefe an Ludwig von Ficker. Brenner Studien 1. Salzburg: Müller.

- (1974/1977): Letters fo Russell, Keynes and Moore. Oxford: Basil Blackwell.
- (1980b): Briefwechsel. Frankfurt/Main: Suhrkamp.

- (1980b): Culture and Value. G. H. von Wright, ed. Oxford: Basil Blackwell.

- (1982): Letzte Schriften über die Philosophie der Psychologie, Band I, Vorstudien zum zweite teil der «Philosophischen Untersuchungen» / Last Writtings on Philosophy of Psychology, Volume I, Preliminary Studies for Part II of «Philosophical Investigations». Edición bilinguie preparada por G.H.Von Wright y Heikki Nyman, Basil Blackwell, 1982. Trad.: Ultimos Escritos sobre Filosofía de la Psicología, Tecnos, Madrid, 1987.

Wright, G. H. von ed. (1982): Wittgenstein. Oxford: Basil Blackwell.

Wünsche, K. (1985): Der Volksschullehrer Ludwig Wittgenstein. Frankfurt/Main: Suhrkamp.

Zeibig, E. (1989): Arbeiten auf den Gebiet des Luftzeugbaues. In: Huter ed., Wittgenstein. Biographie, Philosophie, Praxis. Vienna: Wiener Secession.

Zemach, E. (1984): Wittgensteins philosophy of the rnystical. In: Review of Metaphysics, 18, pp. 39-57.

Zweig, M. (1987): Lebenserinnerungen. Genlingen: Bleicher.

\section{NOTAS}

'La «breve» bibliografía sobre el tema, sobre todo si la comparamos con la suscitada por el Wittgenstein filósofo, se menciona (en parte) al final de este trabajo, sin embargo quiero citar aquí por su importancia el trabajo de J. Turnovsky (1987) Die Poetik eines Mauervorsprungs. Braunschweig/Wiesbaden: Vieweg, y el trabajo de Paul Wijdeveld, Ludwig Wittgenstein. Architect, The Pepin Press, The Netherlands, 1993, al que debo la mayor parte de las referencias históricas sobre la casa y el análisis arquitectónico del edificio

${ }^{2}$ El panfleto al que se refiere Wittgenstein debe ser Richtlinien für ein Kunstamt (Direcciones para un Ministerio de Arte) de 1919, que junto con Architektur de 1910 constituyen los principales trabajos teóricos de Loos. En ese escrito Loos solicita un proteccionismo del arte por parte del estado apoyándose en el rol histórico que se ha pensado del artista en la sociedad. Fue a través del artista que la Providencia, el Espíritu Santo, provocó la civilización y el florecimiento cultural del hombre

${ }^{3}$ L. Wittgenstein. Letzte Schriften über die Philosophie der Psychologie, Band I, Vorstudien zum zweite teil der «Philosophischen Untersuchungen»/Last Writtings on Philosophy of Psychology, Volume I, Preliminary Studies for Part II of «Philosophical Investigations». Edición bilingüe preparada por G. H. Von Wright y Heikki Nyman, Basil Blackwell, 1982. Existe traducción al castellano en Tecnos, Madrid, 1987, por la que cito.

4 Paloma García Abad y Arantxa Martín Santos leyeron versiones previas de este artículo sugiriéndome numerosas correcciones y comentarios. Expreso aquí mi agradecimiento aunque, naturalmente, los errores que hayan sobrevivido son de mi responsabilidad. 


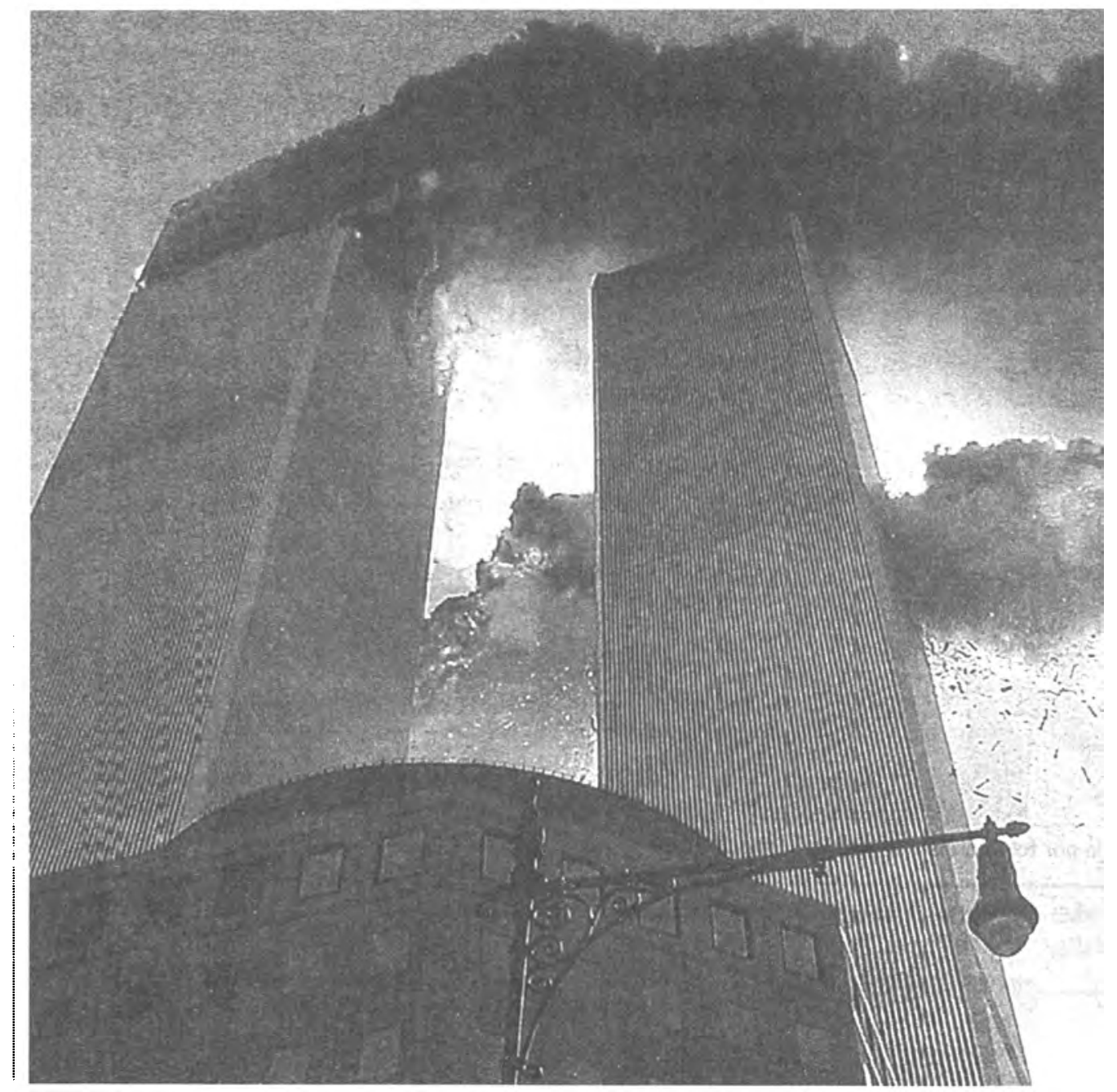

«No, dijo Zaratustra, tú has hecho del peligro tu profesión, en ello no hay nada que despreciar. Ahora pereces a causa de tu profesión: por ello te voy a enterrar con mis propias manos»*.

(Prólogo de Así habló Zaratustra)

* Citado por Peter Sloterdijk en «El pensador en escena», El materialismo en Nietzche, Pre-textos, pág. 23. 